\title{
The Use of Laser Scanner in Caves, Encountered Problems and Solution Suggestion
}

\author{
Murat Yakar ${ }^{1, *}$, Ali Ulvi², Ahmed Suat Toprak ${ }^{3}$ \\ ${ }^{1}$ The Faculty of Engineering and Architecture, Topographical Engineering, Selcuk University, Turkey \\ ${ }^{2}$ The Vocational School of Hadim, Selcuk University, Turkey \\ ${ }^{3}$ KOP Region of Development Administration, Turkey
}

Copyright $(2016$ by authors, all rights reserved. Authors agree that this article remains permanently open access under the terms of the Creative Commons Attribution License 4.0 International License

\begin{abstract}
Cavity extending into a hillside or rock is named as a cave. If the caves occur during hardening of rocks, they are called as the first group cave. Volcanic caves, lava tubes, lava caves, coral caves are this kind of caves. If the caves occur as a result of mechanical and chemical erosion of the rocks, they are called as the second group cave. Turkey has many caves due to the nature of different land. Many of them are unknown, even if a small part of them are known, the information cannot be taken from them adequately. Some undesirable effects can occur such as slowing down in the formation and development of caves, algae formation because the caves are vulnerable to the human impact. Therefore, in touristy caves, it is necessary to employ many engineering applications to protect the caves and visitors. Maps with high details are needed for these applications. The methods used to produce maps of the cave vary according to the structure of the cave. However, together with today's changing and evolving technology, used tools and equipment in the cave mapping vary as well. The aim of this study was to measure the availability of terrestrial laser scanners in removing the three-dimensional model of the caves and to provide solutions to the problems encountered. It is understood that the terrestrial laser scanners are usable for the cave mapping and method that allows the users to obtain accurate and detailed information for the objects that are scanned in a little while at the end of the study.
\end{abstract}

Keywords Terrestrial Laser Scanning, Point Cloud, 3D Model, Cave

\section{Terrestrial Laser Scanning Technology}

It is a technology which provides to get 3 dimensional coordinations of objects directly, delicately and automaticly [5]. It has an application area in registration procedures of cultural heritage and especially in the engineering projects
[6]. This technology can be used in the work of cultural heritage and archeological areas for different purposes to form 3 dimensional models with high precision, to have high incidence of detail about the object and coupling [7].

In the works of documentation, cultural properties to scan small sculptures, objects, close-range scannings, which work with the method of triangulation, are used. The scannings which is used with phase comparing method and with stream-arrival time of laser beam, is used in the works of documenting of historical building, archeological areas and big areas [8].

Terrestrial Laser Scanning Technology Terrestrial laser scanning technology is a new developing technology which is used for $3 \mathrm{D}$ modeling of the objects. Today, the most popular measuring system for laser scanners is "Time of flight" [9]. This technique enables to measure the identified distance for several 100 meters. Besides, phase measuring principle is another partner technique. At this technique distance is limited in 100 meters. Accuracy of measured distance is just a few $\mathrm{mm}$. [10]. Some terrestrial laser scanners can measure up to several $\mathrm{m}$. Those are used in more industrialized applications. Optic triangulation is the kind of distance measuring principle which is used in this kind of terrestrial laser scanners. The accuracy of these measures is at micron levels. Terrestrial laser scanners can be group according to their technical features below [11].

Table 1. The classification of terrestrial laser scanner

\begin{tabular}{|c|c|c|}
\hline MEASURING SYSTEM & DISTANCE $(\mathrm{m})$ & ACCURACY $(\mathrm{mm})$ \\
\hline Time Of Flight & $<100$ & $<10$ \\
\cline { 2 - 3 } & $<1000$ & $<20$ \\
\hline Phase Measuring & $<100$ & $<10$ \\
\hline Optic Triangulation & $<5$ & $<1$ \\
\hline
\end{tabular}

With the latest developments at terrestrial laser scanners, the minimum scanning distance decreased to $30 \mathrm{~cm}$.

\subsection{The Differences that Differs the Terrestrial Laser}




\section{Scanners from Traditional Measuring Techniques}

The most effective way of terrestrial laser scanners is capturing the 3D geometry of the objects directly, fast and detailed. Other advantages in order: [12]

1- The impressive decrease of expenditures

2- Completing the Project much faster. The Project can be completed in a few days.

3- It can measure at complex, in accessible, dangerous objects and areas where the traditional techniques failed.

4- As the scanning process does not depend on the lighting. It is possible to scan even at night.

5- Completeness and comprehensiveness at scanning: It can capture everything at one time. Thus, if any information is needed, it is not necessary to go back to the scaning area. This also raises the trust of the user fort the result.

6- From now on, multiple purposed data usage.

\subsection{The laser telemetry}

A laser telemeter is composed of:

- A transmitter (solid state laser or laser diode semipermeable)

- Receiver channel (Auto-Sensing Control (AGC), detectors, amplifiers)

- Time and time differential measurement unit (digital converter (TDC))

- Transmitter and receiver optics

Laser transmitter, one sent and the receiver starts the time measurement unit emits divided into two parts, the initial laser pulse is sent to other objects (Figure 1). Sensors are used to detect the backscattered laser signals from the object surface. When the scanned object's surface is reached, the laser pulses scattered back and returns a part of the detector. The power of the laser pulses, are converted to electric current. The received amount of power, because the audio signal rate and distance that affect the sensitivity, it is important to analyze this relationship. As mentioned, a portion of the scattered laser power will return to the browser. Taken laser power, power is given a very small part, and depends on changes in the target image. Auto-sensing control (AGC) by adjusting the measurement time, taken my pulse dynamics can be realized by reducing the optical or electrical. The backscattered part of the laser pulses, after detecting, running time and stop timing when the measurement unit is sent to separatists [2].

\subsection{Application areas of Terrestrial Laser Technology}

Terrestrial laser scanning technology is used in many areas of 3D modeling. This technology is also used extensively in the areas listed below [1], [3], [4]

In the mining industry,

The documentation of industrial structure,

Archeology

In architecture,

Date and archiving of cultural heritage and preservation,

Automotive industry and robotic application,

Measurement and GIS applications,

Coastline identified in the work

In volcano monitoring,

In forestry work,

Deformation studies,

In environmental application

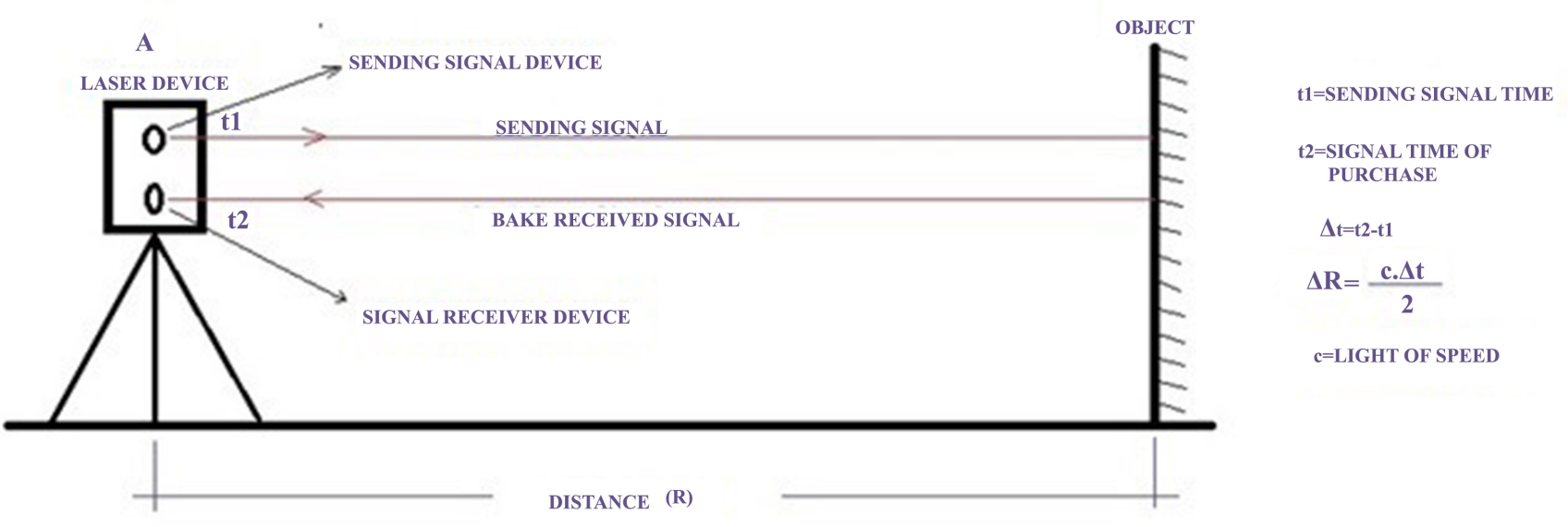

Figure 1. A typical pulsed laser telemeter, the operating principle 


\section{Case Study}

The cave which we modelled with terrestrial laser scanning method is located within the boundaries of Hadim, Konya. The coordinates are $36^{\circ} 58^{\prime} 50.82^{\prime \prime} \mathrm{N}$ and $32^{\circ} 23^{\prime} 56.78^{\prime \prime}$ E. ( Figure 2).

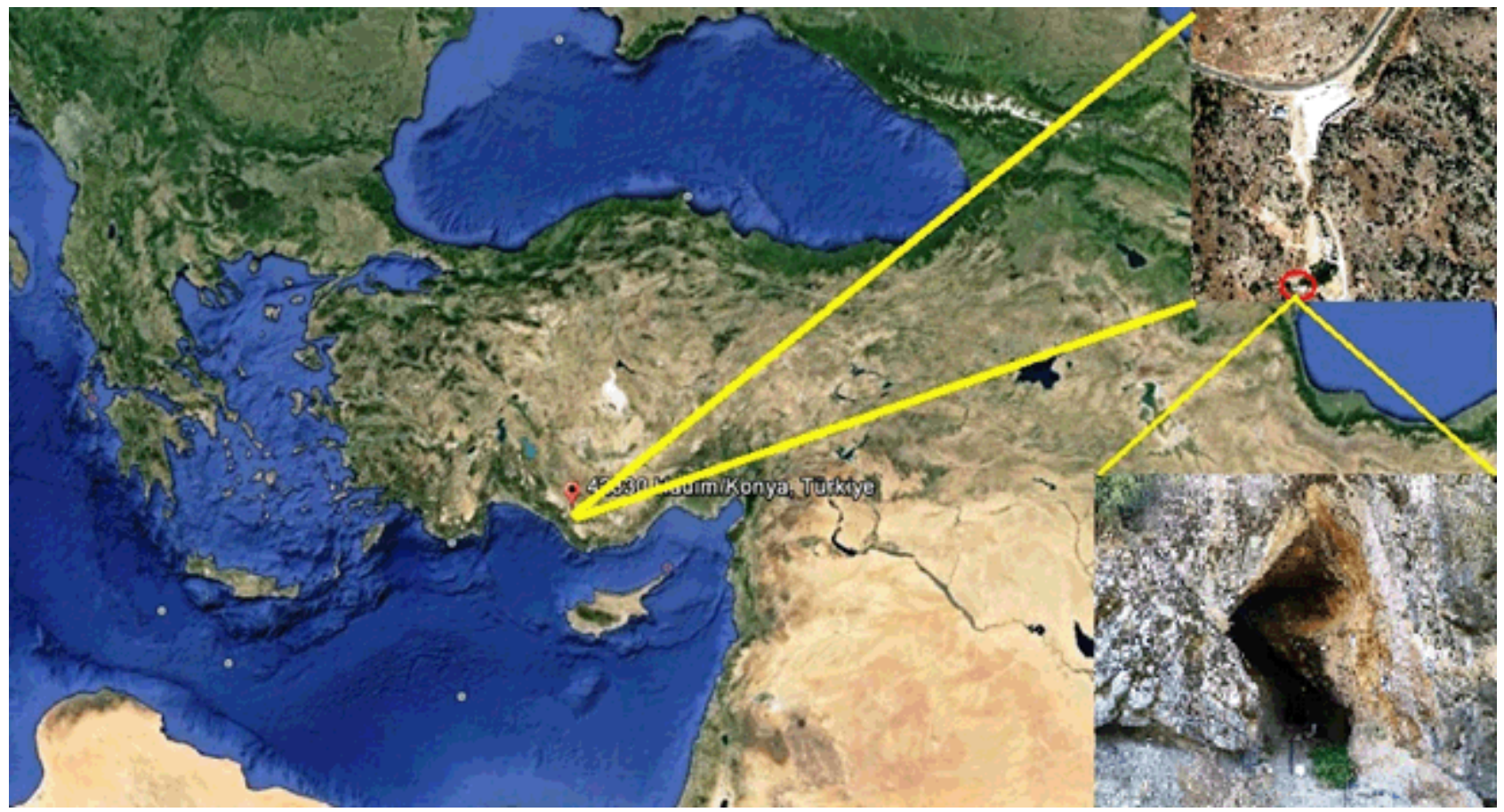

Figure 2. The cave location on the world

\section{Material-Method}

During the pre-study process of modeling the cave, laser scanner) and electronic total station (Figure 4), the target papers which are stuck on the walls, are provided (Figure 5)
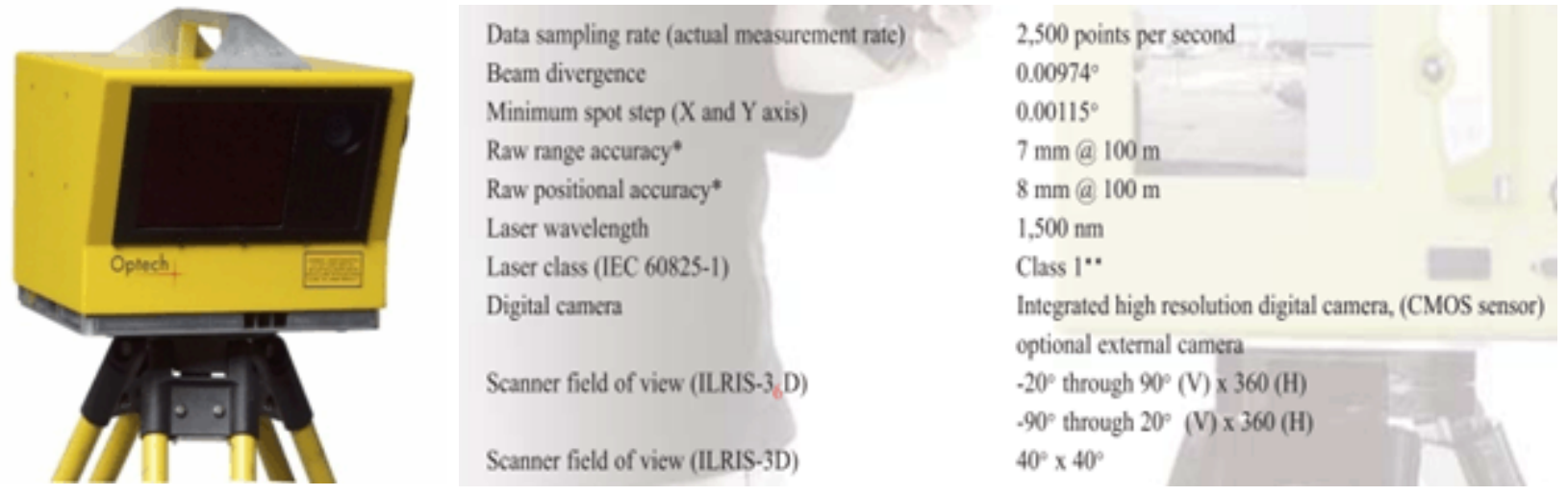

Figure 3. Optech Ilris 3D laser scanner and technical specifications 


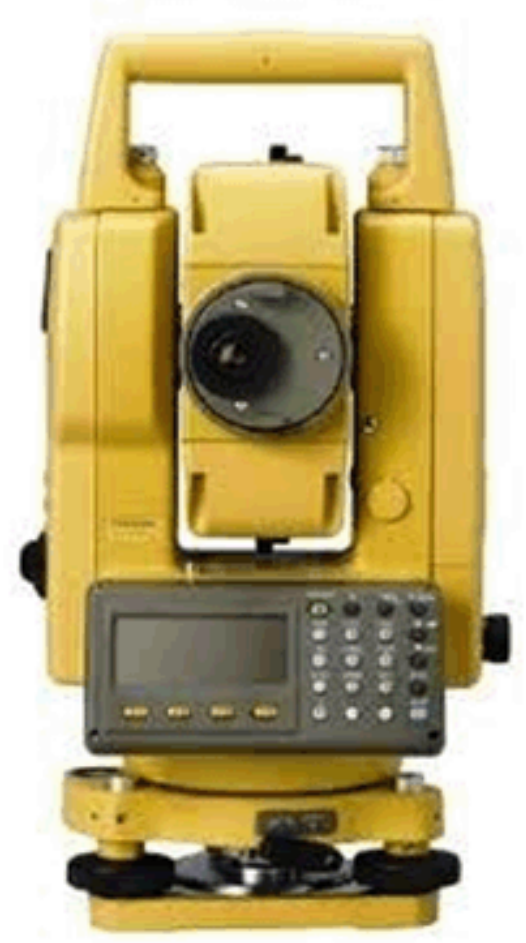

\begin{tabular}{|c|c|}
\hline Model Name & GPT-3007 \\
\hline \multicolumn{2}{|l|}{ TELESCOPE } \\
\hline Length & $150 \mathrm{~mm}$ \\
\hline Objective Lens Dia & $45 \mathrm{~mm}$ (EDM 50mm) \\
\hline Magnification & $30 \times$ \\
\hline Image & Erect \\
\hline Field of View & $1^{\circ} 30^{\prime}$ \\
\hline Resolving Power & $2.8^{\prime \prime}$ \\
\hline \begin{tabular}{|l|l} 
Min. Focus Distance \\
\end{tabular} & $1.3 \mathrm{~m}(4.29 \mathrm{ft})$. \\
\hline \multicolumn{2}{|c|}{ DISTANCE MEASUREMENT } \\
\hline \multicolumn{2}{|c|}{ Measuring Range } \\
\hline Non-prism Mode & (Target: Kodak White) \\
\hline $\begin{array}{l}\text { In low light condition and } \\
\text { without sun glare on target }\end{array}$ & 1.5 to $250 \mathrm{~m}(5$ to $820 \mathrm{ft}$. $)$ \\
\hline \multicolumn{2}{|l|}{ Prism Mode } \\
\hline $\begin{array}{l}\begin{array}{l}\text { Condition } 1^{*} \\
(1 \text { prism })\end{array} \\
\end{array}$ & $3,000 \mathrm{~m}(9,900 \mathrm{ft})$ \\
\hline \multicolumn{2}{|l|}{ Measurement Accuracy } \\
\hline Non-prism Mode & (Diffusing Surface) \\
\hline 1.5 to $2.5 \mathrm{~m}(5$ to $82 \mathrm{ft}$. $)$ & $\pm(10 \mathrm{~mm}) \mathrm{m}$.s.e. \\
\hline $\begin{array}{l}25 \mathrm{~m} \text { or more }(82 \mathrm{ft} . \text { or } \\
\text { more) }\end{array}$ & $\pm(5 \mathrm{~mm}) \mathrm{m}$.s.e. \\
\hline Prism Mode & $\begin{array}{c} \pm(3 \mathrm{~mm}+2 \mathrm{ppm} \times \mathrm{D}) \mathrm{m} . \text { s.e. D:Measuring distance } \\
(\mathrm{mm})\end{array}$ \\
\hline
\end{tabular}

Figure 4. Total Station GPT 3007 and technical specifications

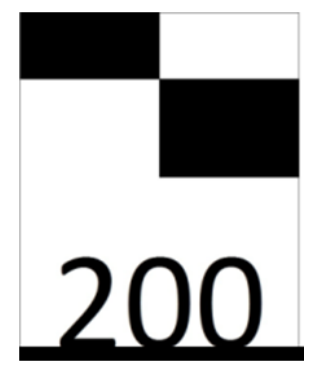

Figure 5. A4 photocopy paper shaped target sheet

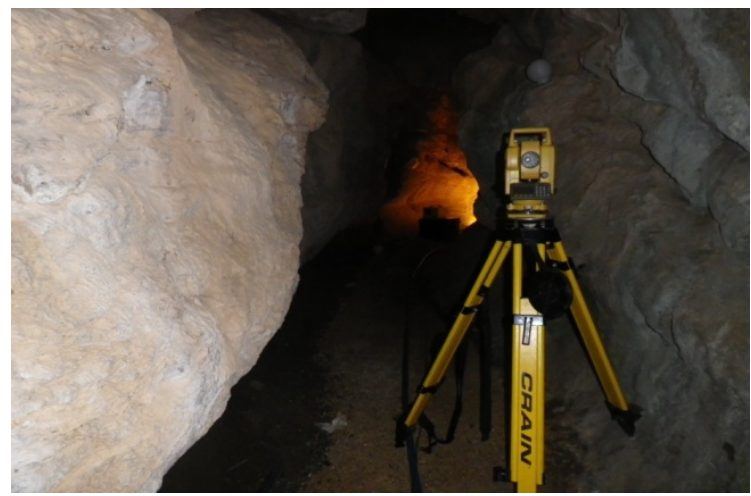

Figure 6. The coordination of the control points with total station
After the preparations had finished at the field, the measurement of the control points at the study started. Angles and distances are measured by Total Station GPT 3007 laser and vertical, horizontal and oblique distances are measured by laser Total Station. And also coordinates are obtained with these devices. (Figure 6)

\subsection{The Application of Terrestrial Laser Scanning at Cave}

The study which we applied has two processes. One is at the area, the other one is at the office. The area work includes scanning the area with laser scanning devices. Office work includes the transferring of data to computers or to suitable applying devices which is obtained during the area work. The area work takes 1 day and Office work takes 3 days long.

The scanning of the cave with terrestrial laser scanning is applied on thirteen different scanning stations. Each scanning is applied at the partner points with in at least 4 link points (Figure 10) .The scanning process is applied Optech Ilris 3D laser scanning device within $0.8 \mathrm{~cm}$ points density (Figure 8). The scanning process is controlled by its own controller programme of the scanner "controller". (Figure 7) 


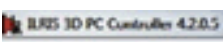

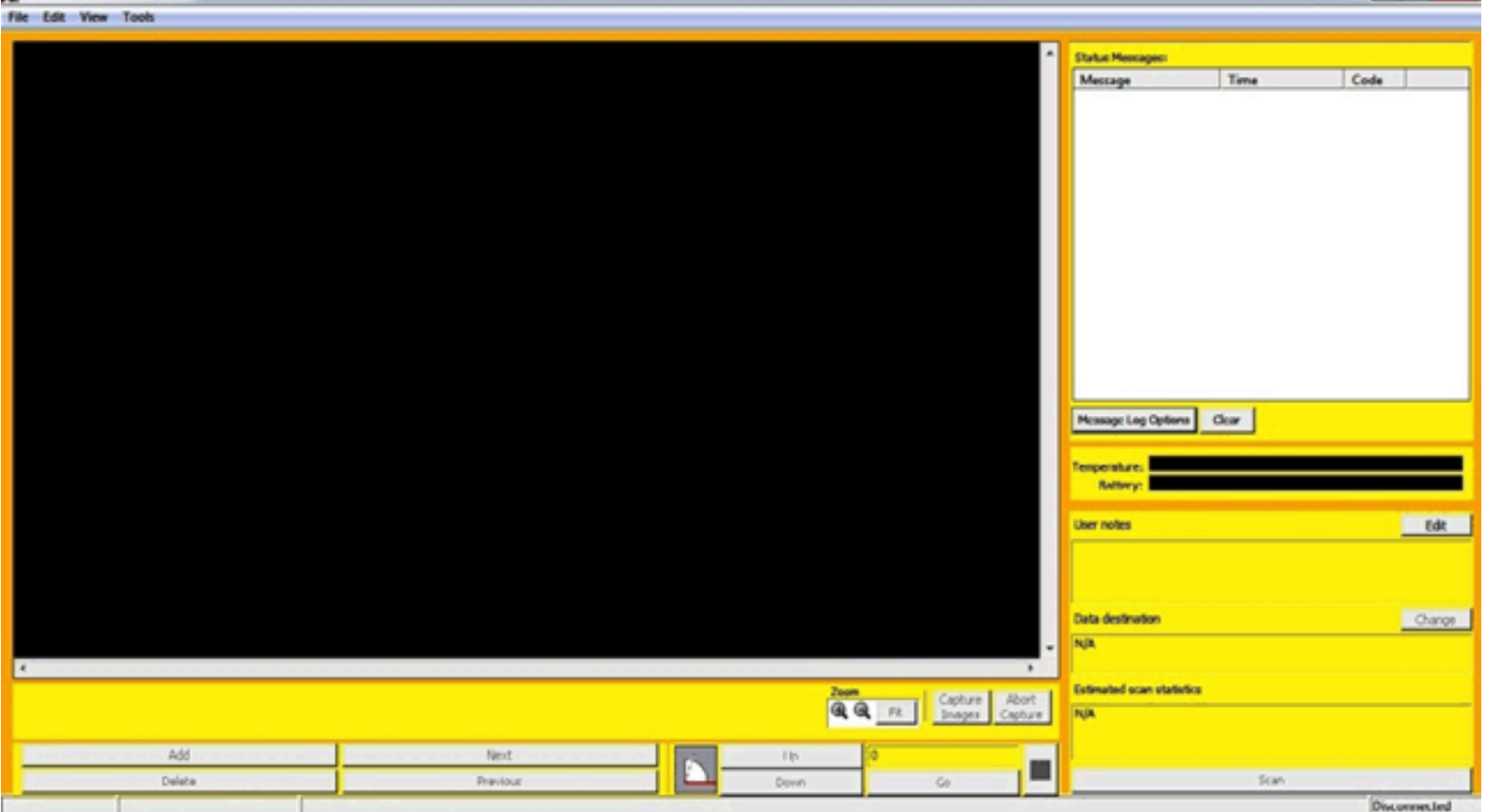

Figure 7. The interface of the controller programme
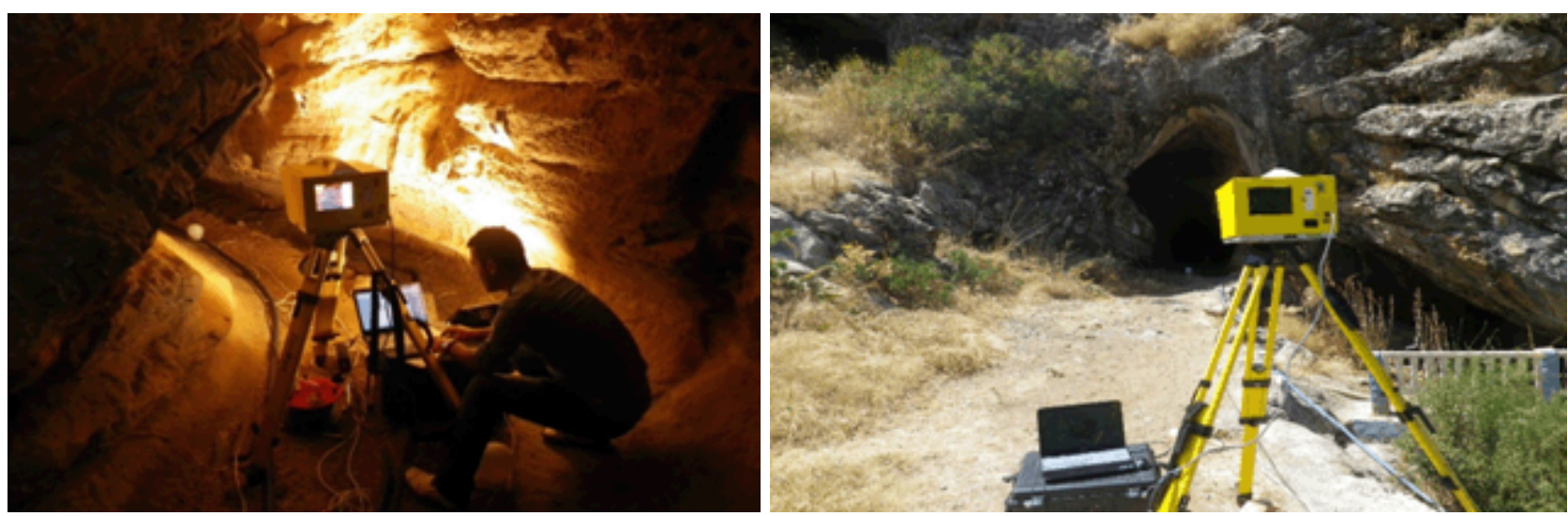

Figure 8. The terrestrial laser scanning process at the field 


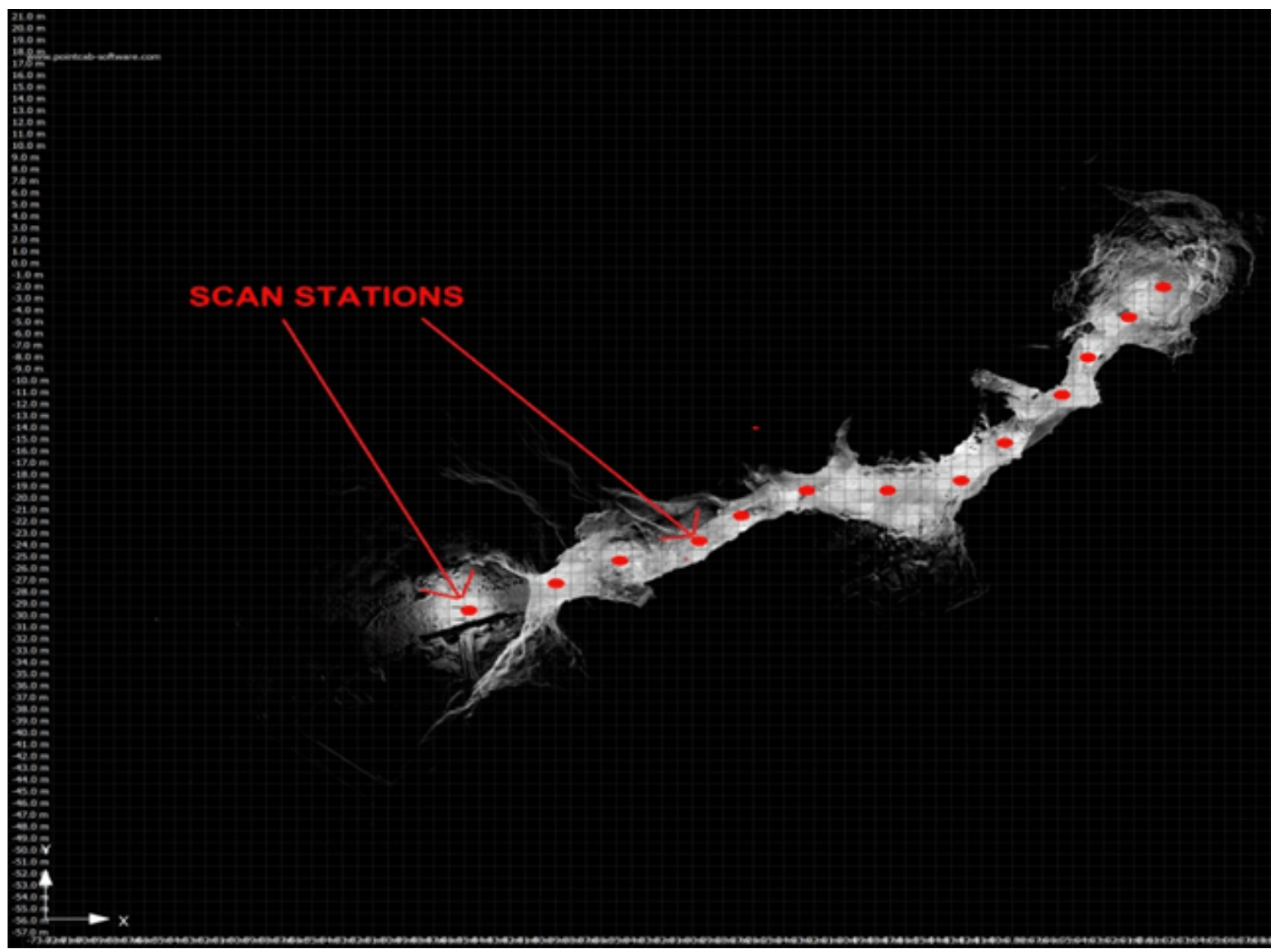

Figure 9. Scan Stations

At first, the data which are collected during the field work, are transformed into PIF, XYZ, RAV, IXF extensions etc. by Parser programme. (Figure 10)

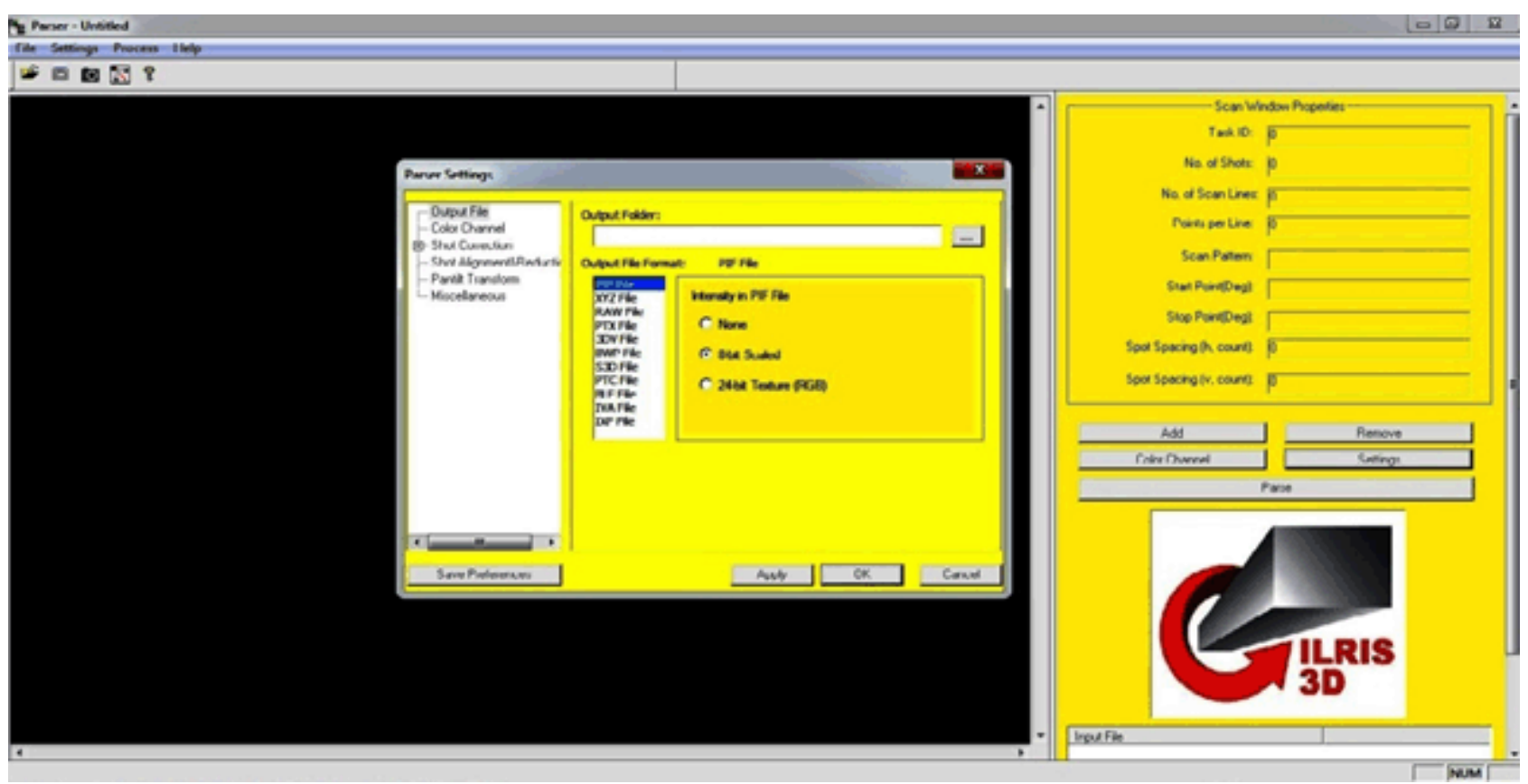

Figure 10. The interface of parser programme 
The files, whose extension are transformed, then opened with polyworks programme and combined with it. (Figure 11) The combination process is applied while two different point clouds partner point is defined. (Figure 12) At the end of this process, the point clouds of the cave are obtained.

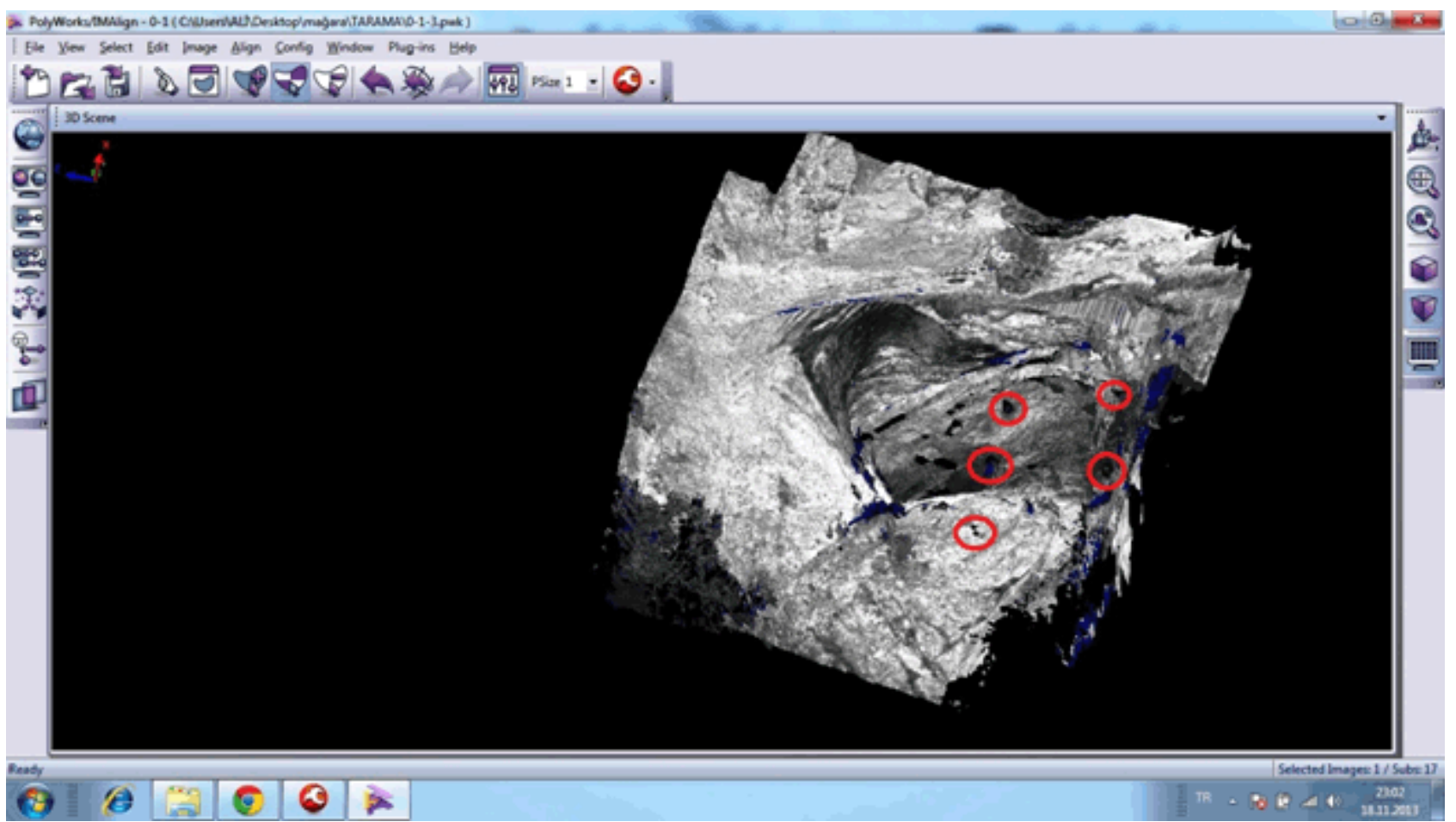

Figure 11. point clouds of cave

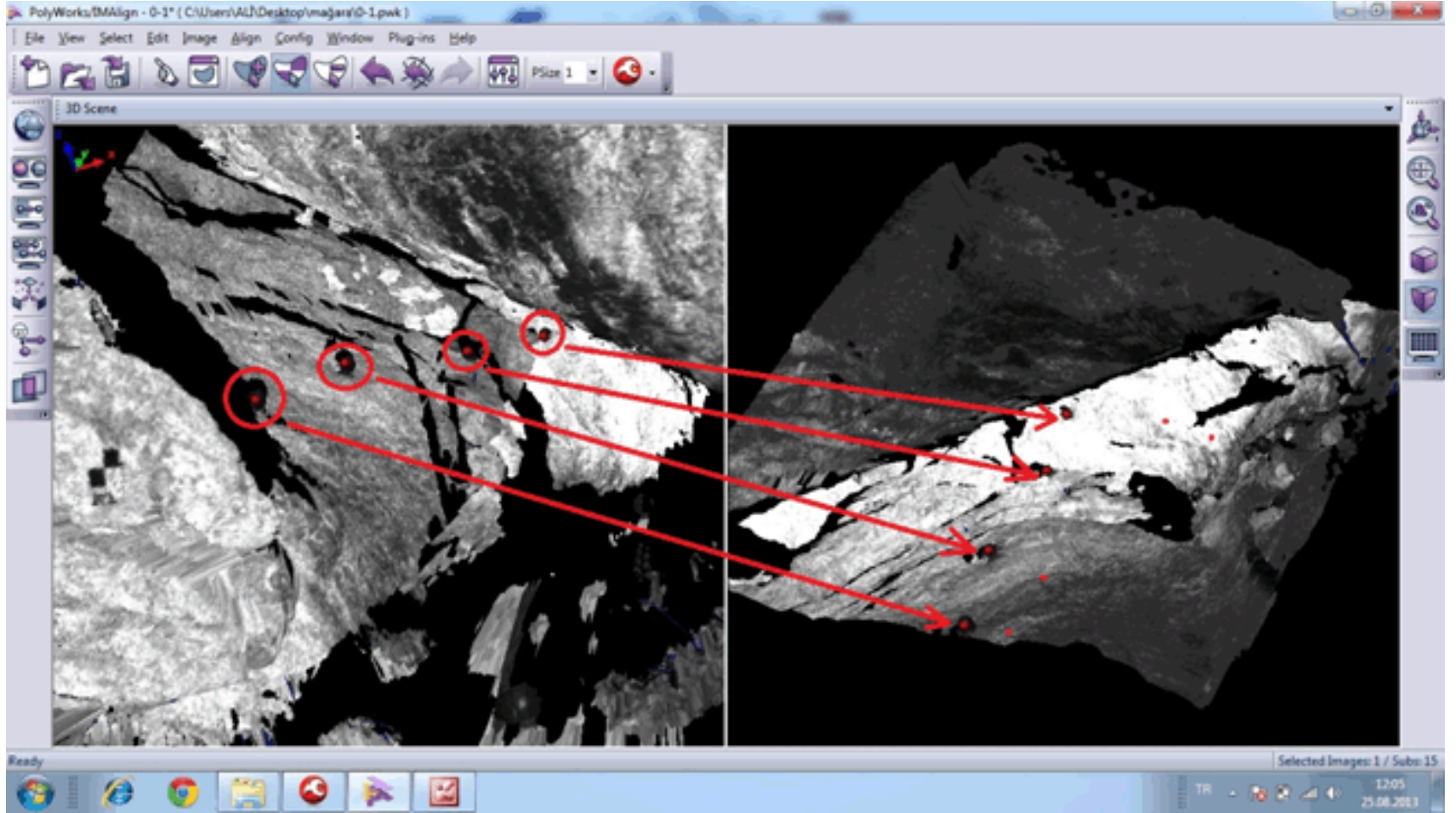

Figure 12. Matching point clouds of cave 


\subsection{Results of Scanning}

Laser scanning was done with OPTECH ILRIS 3D laser scanning from 13 different stations and with $0.8 \mathrm{~cm}$ space. Every scanning was done at least 4 linkups in mutual areas.

Coordinates of points (10.174.811pieces) obtained from scanning, were transformed general coordination system. Using laser scanner is very difficult in narrow areas. Scanning locations of laser scanner is very important. Many laser scanners minimum scanning range is very long. Some of them have $2 \mathrm{~m}$ for minimum sannening range. If the cave narrow, that is if it is about $1 \mathrm{~m}$, scanning process cannot be completed. Laser scanners minimum scanning range should be taking into consideration.

In caves, there is no certain figure to combine data. Combining of point cloud need a known points for all data set. For this aim, using targets is useful to combine data.

\section{Conclusions}

In the end of this study;

- It is shown that the tools and equipment used for the screening should be elaborated before starting the work due to the fact that the cave surveys are very special studies.

- In particular, it is not easy to employ the laser device in narrow crossing region of caves, on account of this, the using of different techniques and methods can be influential for better model.

- Terrestrial laser scanners are effective devices in the digitalization of the caves and 3-dimensional data acquisition. Information about the seismicity of the region in caves formed on the active faults can be produced by the $3 \mathrm{D}$ model obtained and identifying the broken crack system of the caves.

- Prepared 3D model can assist to determine the age of the cave in a collaborative study together with geologist.

- The 3D model obtained can be employed to demonstrate the cave map, plan view.

- The 3D model in this study will underlie to the planning and GIS work related to tourism in the cave.

When it is wanted to model the cave, before measuring process, the physical conditions of the cave should be inspected.

Because the laser scanning tools are all different from each other. At this point, the scanning machine which has the nearest scanning ability should be choosen. (For Ex: $30 \mathrm{~cm}$ ). If this condition isn't recognized, the physical structure of the cave can't be scanned properly and as a result of this, more scanning needs to be done. This causes time wasting.

Lighting of the cave before scanning ensures the colored scanning of the cave. And this is going to be a source for 3D visualization of the cave.

\section{REFERENCES}

[1] Alshawabkeh, Y., Haala, N., 2004, "Integration of Digital Photogrammetry and Laser Scanning for Heritage Documentation", ISPRS xx. Symposium, Com. V., WG 4, 12-23 July 2004, İstanbul.

[2] Amann, M-Ch., Bosch, T., Lescure, M., Myllylä, R. and Riox, M., 2001. Laser ranging: a critical review of usual techniques for distance measurement. Optical Engineering, 40 (1), pp. $10-19$.

[3] Bitelli, G., Dubbini, M., Zanattu, A., 2004, “Terrestrial Laser Scannimg and Digital Photogrammetry Tecniques to Monitor Landslide Bodies" ISPRS xx. Symposium, Com. V., WG V/2, 12-23 July 2004, İstanbul.

[4] Bornaz, L., Lingua, A., Rinaudo, F., 2004,'Engineering and Environmental Applications of Laser Scanner Tecniques", ISPRS xx. Symposium, Com. V., WG V/4, 12-23 July 2004, İstanbul.

[5] Reshetyuk, Y. "Self-Calibration and Direct Georeferencing in Terrestrial Laser Scanning", Doctoral thesis in Infrastructure, Geodesy, Royal Institute of Technology (KTH), Department of Transport and Economics Division of Geodesy, 2009.

[6] Licht1, D. D., Gordon, S.J. "Error Propagation in Directly Georeferenced Terrestrial Laser Scanner Point Clouds for Cultural Heritage Recording", FIG Working Week, Athens, Greece, May 22-27, 2004. Teknolojik Araştırmalar: HTED 2012 (1) 1-18 Mimari Belgelemede Yersel Lazer Tarama Yönteminin Uygulanmas1.

[7] Fabris, M., Achilli, V. Artese, G., Boatto, G., Bragagnolo, D., Concheri, G., Meneghello, R., Menin, A., Trecroci A. (2009). "High Resolution Data From Laser Scanning and Digital Photogrammetry Terrestrial Methodologies Test Site: An Architectural Surface", ISPRS, 2009, Vol. 38, Part 3/W8pages.43-48.

[8] Yastıkl1, N. "Documentation of Cultural Heritage Using Digital Photogrammetry and Laser Scanning", Journal of Cultural Heritage, 2007 vol. 8 issue. (4): pages 423-427.

[9] Fröhlich, C., Mettenlaiter, M., 2004, "Terrestrial Laser Scanning- New Perspectives 3D Surveying”, ISPRS xx. Symposium, Com. V., WG V/4, 12-23 July 2004, İstanbul.

[10] Schulz, T., Ingesand, H., 2004, “Terrestrial Laser Scanning-Investigations and Applications for High Precision Scanning", FIG Working Week, 22-27 May, Athens.

[11] Murat Yakar, Ali Ulvi, Ahmet Suat Toprak, Ömer Mutluoğlu, Laser Scanning and Photogrammetric Evaluation of Uzuncaburç Monumental Entrance, International Journal of Applied Mathematics, Electronics and Computers, http://ISSN:2147-82282147-6799www.atsc ience.org/IJAMEC

[12] Yuriy Reshetyuk "Investigation and calibration of pulsed time-of-flight terrestrial laser scanners" Department of Transport and Economics Division of Geodesy 10044 Stockholm 